\title{
Gestão de resíduos de equipamentos eletroeletrônicos em instituições de ensino superior
}

O objetivo do trabalho é caracterizar uma prática de gestão correta de resíduos de equipamentos eletroeletrônicos em uma instituição de ensino superior subsidiando a definição de estratégias para potenciais implantações de programas de gerenciamento desses resíduos no âmbito das Universidades, atendendo as diretrizes estabelecidas na política nacional de resíduos sólidos. Utilizou-se um estudo de caso, avaliando os procedimentos de manejo de resíduos de equipamentos eletroeletrônicos no Centro de Descarte e Reúso de Resíduos de Informação (CEDIR) da USP. Para este trabalho foram utilizados dados de resíduos de equipamentos eletroeletrônicos disponíveis no sistema de informações da Universidade. Um dos problemas enfrentados pelas Instituições de Ensino Superior é a questão da gestão adequada dos resíduos de equipamentos eletroeletrônicos (REEE). Muitas instituições não apresentam um plano de gestão, e os resíduos de equipamentos eletroeletrônicos acabam sendo armazenados, impossibilitando seu reaproveitamento. Foram contabilizados diferentes tipos de resíduos de equipamentos eletroeletrônicos na instituição. Verificou-se que o principal resíduo de equipamento eletroeletrônico recebido pela instituição são os equipamentos de informática. Aplicou-se a metodologia SWOT para a análise de uma proposta de gestão de resíduos de equipamentos eletroeletrônicos em Universidade. A gestão dos resíduos de equipamentos eletroeletrônicos em instituições de ensino superior é bem complexa, pois envolve a questão de patrimônio, espaços de armazenamento adequado, práticas de manejo correto e reaproveitamento e, em especial devido à grande variedade de equipamentos, de difícil reúso e, principalmente reciclagem.

Palavras-chave: Resíduos de Equipamentos Eletroeletrônicos (REEE); Gerenciamento de REEE; Instituições de Ensino Superior.

\section{Management of waste electrical and electronic equipment in higher education institutions}

\begin{abstract}
The objective of the study is to characterize a practice of correct management of waste electrical and electronic equipment in a higher education institution, subsidizing the definition of strategies for potential implantation of waste management programs within the Universities, in accordance with the guidelines established in the policy of solid waste. We used a case study, evaluating the waste management procedures of electrical and electronic equipment at the Center for Disposal and Reuse of Information Waste (CEDIR-USP). We used data of waste electrical and electronic equipment available in the university information system. One of the problems faced by Higher Education Institutions is the issue of the correct management of waste electrical and electronic equipment. Many institutions do not present a management plan, and waste electrical and electronic equipment ends up being stored, making it impossible to reuse it. Different classes of waste electrical and electronic equipment were identified in the institution. The main waste of electrical and electronic equipment received by the institution was information technology. Application of the SWOT methodology in the analysis of a proposal for the management of waste electrical and electronic equipment in university. The management of waste electrical and electronic equipment in institutions of higher education in a great complexity, as it involves the patrimony issue, adequate storage spaces, practices of correct management and reuse and, mostly due to the considerable diversity, increasing the recycling difficult.
\end{abstract}

Keywords: Waste Electrical and Electronic Equipment (WEEE); WEEE Management; Higher Education Institutions.

Topic: Logística Reversa

Reviewed anonymously in the process of blind peer.
Received: $12 / 08 / 2019$

Approved: 27/09/2019
Fábio Pires Watanabe

Universidade Federal de São Paulo, Brasil http://lattes.cnpq.br/5801547515092893 http://orcid.org/0000-0002-5810-8140 fabiopw9@gmail.com

Giovano Candiani (iD)

Universidade Federal de São Paulo, Brasil http://lattes.cnpq.br/9950995765229751

http://orcid.org/0000-0001-9896-4390

giovanocandiani@gmail.com

\section{Referencing this:}

S WATANABE, F. P.; CANDIANI, G.. Gestão de resíduos de equipamentos eletroeletrônicos em instituições de ensino superior. Revista Ibero Americana de Ciências Ambientais, v.10, n.5, p.169186, 2019. DOI: http://doi.org/10.6008/CBPC21796858.2019.005.0016 


\section{INTRODUÇÃO}

A gestão dos resíduos de equipamentos eletroeletrônicos (REEE) se tornou um enorme desafio, pois cada vez mais, as quantidades geradas são crescentes e rapidamente tornam-se obsoletos. O problema se agrava na medida em que os REEE são perigosos a saúde humana e ao meio ambiente, causando contaminações a sua exposição pela presença de metais pesados em sua composição.

O relatório Global E-Waste Monitor (2017) elaborado pela Universidade das Nações Unidas, União Internacional de Telecomunicações e pela Associação Internacional de Resíduos Sólidos, aponta que, no ano de 2016, foram produzidos 44,7 milhões de toneladas de REEE no mundo, uma geração per capita de 6,1 $\mathrm{kg} /$ habitante/ano. Ainda segundo este relatório, o Brasil é o maior produtor de REEE da América Latina e o segundo de todo o continente americano, produzindo 1,5 milhões de toneladas e ficando atrás apenas dos Estados Unidos (6,3 milhões de toneladas). Estima-se que no ano de 2016, cada brasileiro produziu cerca de 7,4 kg de REEE (BALDÉ et al., 2017).

Os resíduos de equipamentos eletroeletrônicos ganharam maior destaque em relação aos seus efeitos danosos a saúde e ao meio ambiente na Europa, com estudos demonstrando esta ocorrência e, a partir disso, foram elaboradas diretivas (normas regulamentadoras) para gestão adequada desses resíduos como um todo. Estas normas determinam instruções para destinação correta, formas de reciclagem e Reúso.

No Brasil, apesar da existência de regulamentações, ainda demanda maior aplicabilidade destas quanto a gestão adequada desses resíduos. Nesse sentido, ainda é um enorme desafio operacionalizar práticas mais adequadas e sustentáveis a gestão desses resíduos como um todo, faltando a implantação de sistemas de logística reversa, educação ambiental e inclusão social de catadores.

A melhor compreensão da gestão do resíduo eletroeletrônico é de alta relevância. O chamado resíduo eletrônico, resíduo eletroeletrônico, lixo eletrônico ou lixo tecnológico, corresponde ao equipamento eletroeletrônico, que teoricamente não possui mais utilidade ao consumidor. Também conhecido como elixo ou e-waste, em inglês (WEEE - Waste Electrical and Electronic Equipment), este é composto por materiais.

Um tipo de resíduo eletrônico bem comum é o computador pessoal (personal computer, PC) cada vez mais acessíveis pelos baixos preços, facilidade de obtenção e também cada vez mais facilmente substituídos devido a sua obsolescência programada, o que é muito preocupante, pois a quantidade de resíduo eletrônico é muito crescente a cada dia (MORALES, 2014).

Assim, neste cenário, a informação e a educação se fazem extremamente necessárias para que haja o descarte correto desses eletroeletrônicos e as Instituições de Ensino Superior, são espaços formais fundamentais no sentido de se desenvolver práticas adequadas quanto a gestão dos resíduos de equipamentos eletroeletrônicos.

Para melhor entendimento da gestão de resíduos eletroeletrônicos em uma Instituição de Ensino Superior, procurou-se o Centro de Descarte e Reúso de Resíduos de Informática - CEDIR na Universidade de São Paulo (USP) para compreender seu funcionamento e implementação de práticas de Reúso e descarte 
sustentável de resíduos eletroeletrônicos. Tratando-se de uma instituição de referência na gestão destes resíduos, a ideia fundamental é compreender melhor estas práticas e com isto, propor diretrizes e estratégias de gestão dos resíduos eletroeletrônicos na Universidade Federal de São Paulo (UNIFESP), Campus Diadema.

As Instituições de Ensino Superior produzem muito resíduo eletroeletrônico e, neste contexto a reciclagem de componentes dos equipamentos eletroeletrônicos, deveria ter mais atenção por parte destas instituições como um todo, pois muitos desses componentes poderiam ser reaproveitados para a remanufatura de computadores mais básicos a serem utilizados em projetos extensionistas, no âmbito de escolas, comunidades e instituições não governamentais, por exemplo, considerando-se a implantação de programas de inclusão digital.

Assim, o objetivo deste trabalho é caracterizar a gestão de resíduos de equipamentos eletroeletrônicos, analisando as práticas do Centro de Descarte e Reúso de Resíduos de Informação, o CEDIR, na Universidade de São Paulo (USP). Para tal, foram definidos como objetivos específicos: (i) analisar o processo de geração, coleta, manejo e Reúso de resíduos de equipamentos eletroeletrônicos em uma Instituição de Ensino Superior, no caso o CEDIR-USP; (ii) identificar os desafios da implementação de um centro de gerenciamento de resíduos de equipamentos eletroeletrônicos e (iii) propor diretrizes, práticas e estratégias de gestão de resíduos de equipamentos eletroeletrônicos na Universidade Federal de São Paulo (UNIFESP), Campus Diadema.

A fim de dar conta dessa tarefa, foi escolhido como instrumento de investigação o método de estudo de caso, incluindo uma visita e coleta de dados disponíveis no CEDIR-USP, levantamento bibliográfico e documental e estabelecimento de diretrizes e estratégias para potencial implantação de um centro de Reúso e reciclagem de resíduos de equipamentos eletroeletrônicos na UNIFESP, Campus Diadema, por meio de um planejamento estratégico se utilizando a análise SWOT.

Além dessa seção introdutória, o presente artigo aborda o referencial teórico sobre resíduos de equipamentos eletroeletrônicos, a reciclagem de resíduos eletroeletrônicos e a gestão desses resíduos em Instituições de Ensino Superior na seção 2, apresenta os procedimentos metodológicos na seção 3, evidencia e discute os resultados na seção 4 e, por último, expõe as considerações finais na seção 5.

\section{REVISÃO TEÓRICA}

\section{Resíduos de Equipamentos Eletroeletrônicos (REEE)}

Os resíduos de equipamentos eletroeletrônicos, REEE são caracterizados como televisores, rádios, telefones celulares, eletrodomésticos portáteis, todos os equipamentos de microinformática, vídeos, filmadoras, ferramentas elétricas, DVDs, lâmpadas fluorescentes, brinquedos eletrônicos e milhares de outros produtos (SMA, 2010). Resíduo eletroeletrônico é todo o resíduo resultante da rápida obsolescência de equipamentos eletroeletrônicos. Apresenta muitos componentes, desde elementos químicos simples a hidrocarbonetos complexos - os metais são os elementos químicos mais encontrados. Plásticos, vidros e compostos cerâmicos também são encontrados nos resíduos eletroeletrônicos (SMA, 2010). 
Vários são os problemas causados pela disposição inadequada destes resíduos, podendo contaminar o meio ambiente como um todo, apresentando riscos à saúde pública. No Brasil, até o ano de 2010 não havia legislação federal específica sobre REEE, entretanto com sancionamento da Política Nacional de Resíduo Sólido (PNRS), a Lei Federal no 12.305/2010, os produtos eletroeletrônicos e seus componentes foram mencionados, no Art. 33, sendo necessária a implementação de sistemas de logística reversa, mediante retorno dos produtos após o uso pelo consumidor, de forma independente do serviço público de limpeza urbana e de manejo dos resíduos sólidos, os fabricantes, importadores, distribuidores e comerciantes de: pilhas e baterias, lâmpadas fluorescentes, de vapor de sódio e mercúrio e de luz e produtos eletroeletrônicos e seus componentes (BRASIL, 2010).

A Política Nacional de Resíduos Sólidos (PNRS), estabelecida por meio da Lei no 12.305 (2010), define que os resíduos eletroeletrônicos são perigosos, sendo, portanto, necessário a elaboração de um sistema de logística reversa e o estabelecimento de acordos setoriais, tornando viável as práticas para Reúso destes resíduos (BRASIL, 2010).

No Art. 3o da PNRS (BRASIL, 2010), acordo setorial é um ato de natureza contratual firmado entre o poder público e fabricantes, importadores, distribuidores ou comerciantes para implementar a responsabilidade compartilhada pelo ciclo de vida do produto. Já logística reversa é um instrumento de desenvolvimento econômico e social, caracterizado por um conjunto de ações, procedimentos e meios destinados a viabilizar a coleta e a restituição dos resíduos sólidos ao setor empresarial, para reaproveitamento, em seu ciclo ou em outros ciclos produtivos, ou outra destinação final ambientalmente adequada.

Ainda na PNRS (BRASIL, 2010) no Art. 33ำ se fala na obrigação compartilhada em estruturar e implementar sistemas de logística reversa, incluindo os produtos eletroeletrônicos e seus componentes, na forma do disposto em regulamento ou em acordos setoriais, ou ainda em termos de compromisso firmados entre o poder público e o setor empresarial.

A gestão de resíduos eletroeletrônicos com a implementação da logística, encontra-se determinado no âmbito da lei, portanto, o setor empresarial deveria sim se responsabilizar muito mais do que somente de maneira compartilhada e efetivamente ser o responsável titular pela implementação e operacionalização dos sistemas de gestão destes resíduos, integrando no processo os municípios e as associações e cooperativas de catadores (FRANCO et al., 2011).

O setor empresarial deveria compensar os serviços ambientais prestados por municípios e cooperativas, pela execução das ações colaborativas na gestão e reciclagem de resíduos como um todo. Uma modalidade de funcionamento de instrumento econômico atual, é o sistema de créditos em logística reversa, que já está funcionando para embalagens, podendo ser implementado com os resíduos eletroeletrônicos (BVRIO, 2019).

Dessa forma, os créditos de logística reversa é basicamente um programa de incentivo ambiental, por meio da remuneração dos catadores pelos serviços de coleta, triagem e destinação adequada dos materiais, de acordo com o volume encaminhado para a indústria, tornando-se uma renda extra para esse público que 
depende de material reciclável, além disso, o programa favorece o fortalecimento de organizações de catadores (BVRIO, 2019).

Os créditos de logística reversa (BVRIO, 2019) são certificados que comprovam um serviço de logística reversa e destinação adequada de uma certa quantidade de resíduos. Esses créditos são emitidos e vendidos por cooperativas de catadores e comprados por empresas que são legalmente responsáveis pela realização da logística reversa (fabricantes e/ou importadores desses produtos). Através da compra de créditos, as empresas estão utilizando e remunerando os serviços de logística reversa realizados pelas cooperativas de catadores e desta maneira cumprir os objetivos e diretrizes da PNRS.

A norma ABNT NBR 16.156:2013 - Resíduos de Equipamentos Eletroeletrônicos - Requisitos para atividade de manufatura reversa, estabelece os requisitos para proteção do meio ambiente e controle dos riscos da segurança e saúde no trabalho na atividade de manufatura reversa de resíduos eletroeletrônicos. A manufatura reversa, é caracterizada pelas etapas da atividade de reciclagem, que compreendem os processos de transformação dos resíduos eletroeletrônicos em partes e peças, insumos ou matérias primas, sem a obtenção de novos produtos.

Na Europa, existe uma normativa válida para a Comunidade Europeia, a Diretiva Europeia no 65 de 2011, na qual os equipamentos eletroeletrônicos são classificados em 11 categorias de acordo com vida útil e composição, entre outros quesitos. Também é estabelecido no âmbito dessa regulamentação, as práticas corretas de gestão dos resíduos eletroeletrônicos.

Conhecer a geração de resíduos de equipamentos eletroeletrônicos é essencial ao planejamento de ações para sua gestão. Atualmente, na ausência de sistemas de gestão no Brasil, são predominantemente destinados ao setor informal de reciclagem. Os resíduos de origem institucional em sua maioria são representados por computadores, substituídos em períodos relativamente regulares. No Brasil, não há estatísticas oficiais sobre a geração de REEE.

Rodrigues et al. (2015) relatam um potencial de geração de REEE, que varia de 2,6 a 3,8 $\mathrm{kg} /$ habitante/ano. Estas autoras realizaram um estudo, que enfatiza o fluxo de REE de origem domiciliar, apresentando um método para cálculo de estimativas de produção e sua aplicação no município de São Paulo/SP. O método aplicado ao município de São Paulo, resultou em 71,9 milhões de REEE, dos quais 8,8 milhões (12,2\%) fora de uso. O valor médio de REEE correspondeu a 18,2 REEE por domicílio; média per capita de 5,3 REEE por habitante. A média de descarte per capita estimada resultou em 4,8 kg/habitante/ano. 0 potencial de geração de resíduos a partir dos REEE fora de uso variou entre 2,9 a 6,0 kg/habitante/ano.

No estado de São Paulo, a Secretaria de Meio Ambiente (SMA) publicou a Resolução SMA no 24 (2010), estabelecendo a relação de produtos geradores de resíduos de significativo impacto ambiental, incluindo no Art. 3o os produtos eletroeletrônicos. No Art. 4ำ, ficam os fabricantes, distribuidores ou importadores dos produtos eletroeletrônicos obrigados a: manter, individualmente ou sob a forma de parcerias, postos de entrega voluntária para os resíduos pós-consumo, orientar os consumidores quanto à necessidade de devolução dos resíduos pós-consumo e cumprir metas de recolhimento. Mas, pergunta-se: Quando se compra um produto eletroeletrônico novo, existe o repasse dessas informações? Habitualmente 
não, cabendo uma cobrança mais efetiva aos fabricantes, no sentido de cumprimento da legislação vigente.

\section{A Reciclagem de Resíduos de Equipamentos Eletroeletrônicos}

A preocupação com a geração de resíduos eletroeletrônicos no Brasil e no mundo é crescente, e vem desafiando várias áreas do conhecimento pela abrangência dos impactos ambientais, econômicos, sociais ou culturais gerados. A reciclagem de resíduos eletroeletrônicos apresenta como maior dificuldade a separação dos materiais que constituem estes resíduos, pois, demandam de processos específicos e alguns casos custos elevados, aspectos que podem inviabilizar o processo. A reciclagem de fios e cabos elétrico de cobre, placas de circuito impresso e outros componentes, que possuem cobre, ouro, platina e outros metais, que têm alto valor comercial, portanto, são mais viáveis economicamente (SMA, 2010).

Os resíduos eletroeletrônicos caracterizados como todos os produtos que dependem do uso de corrente elétrica ou de campos eletromagnéticos para funcionar. E podem ser divididos em quatro categorias/tipos (linhas) de acordo com a Agência Brasileira de Desenvolvimento Industrial (ABDI, 2013): branca (refrigeradores, fogões, lavadoras de roupas, etc.), marrom (televisor, monitores, DVD, câmeras, filmadoras, etc.), azul (batedeiras, liquidificadores, fornos elétricos, furadeiras, etc.) e verde (desktop, notebook, impressoras, celulares, monitores etc.).

Oliveira et al. (2012) salientam que a reciclagem de REEE, consiste nas seguintes etapas: desmontagem (segmentação por desmontagem seletiva e isolamento de componentes perigosos ou valiosos para tratamento especial), aperfeiçoamento (processamento mecânico e/ou metalúrgico para aperfeiçoar os materiais desejáveis e refinamento (purificação dos materiais recuperados, utilizando produtos químicos. O início da reciclagem se dá na separação dos diversos componentes, estes processos podem ser mecânicos ou eletroquímicos. Os processos mecânicos servem para separar os metais das frações de plásticos, vidros e cerâmicas. Já os processos eletroquímicos separam os diferentes metais que se encontram misturados. Após a separação ocorre o beneficiamento dos materiais. As placas de circuito impresso são muito utilizadas em computadores, estas apresentam $49 \%$ de materiais cerâmicos, vidros etc., $19 \%$ de plásticos, $4 \%$ de bromo e $28 \%$ de metais.

As placas de circuito impresso são componentes essenciais dos produtos eletroeletrônicos, cuja composição é bastante diversificada, incluindo metais, como: cobre, alumínio, ferro, chumbo, ouro, prata etc. e outros materiais, tais como: resinas, fibras de vidro, diferentes tipos de plásticos etc., ou seja, muitos componentes tóxicos, porém com inúmeros materiais, que são viáveis para serem recuperados. A reciclagem de placas de circuito impresso, se dá pela segregação e recuperação de diversos componentes. 0 processo de reaproveitamento ocorre por meio de estágios de trituração, separação e recuperação de materiais metálicos e reutilização de materiais não metálicos. A reciclagem de REEE ocorre através da (i) remanufatura, que está associado ao aproveitamento de peças e componentes já usados em um equipamento para a fabricação de um novo equipamento e da (ii) de manufatura, que implica na completa desmontagem do equipamento, seguida da aplicação de processos físico-químicos para separação de matérias-primas, buscando o reaproveitamento de materiais, como: papéis, vidros, plásticos etc. e metais, tais como: níquel, 
mercúrio, zinco, chumbo, cadmio etc. (CAYUMIL et al., 2016).

A reciclagem inicia-se com a trituração do material até frações granulométricas menores a $1 \mathrm{~mm}$, estas frações são separadas magneticamente em um separador magnético de esteira por via seca. O material não-magnético é, então, separado por um separador eletrostático (eletrodos ionizantes), que separa materiais condutores dos não-condutores. Os materiais condutores são beneficiados utilizando-se soluções com substâncias químicas, como ácido sulfúrico, possibilitando a obtenção do cobre, estanho e chumbo separadamente (processo de eletroobtenção). Outros materiais muito reciclados são os fios e cobres (SMA, 2010).

Cayumil et al. (2016) relatam que a concentração de metais preciosos em placas de circuitos impressos de computador é interessante. A concentração de prata, ouro e paládio, na média é de 1.000, 250 e $110 \mathrm{~g} / \mathrm{t}$, respectivamente. Os autores comentam que diversas abordagens metalúrgicas e químicas têm sido utilizadas para recuperar metais preciosos dos resíduos eletroeletrônicos. Ainda segundo os autores, a reciclagem pirometalúrgica (tratamento térmico a alta temperatura (pirólise), faixa de 800 a 1350드) de placas de circuitos impressos de computadores, produz uma parcela carbonácea não metálica e produtos metálicos na forma de folhas ou gotículas de cobre ou estanho e fios com proporções pequenas de prata, ouro etc. Processamentos posteriores, como refinamentos adicionais se tornam necessários e viáveis para a recuperação desses metais preciosos dos resíduos eletroeletrônicos.

\section{A Gestão de Resíduos de Equipamentos Eletroeletrônicos em Instituições de Ensino Superior}

Ainda é bastante incipiente o número de universidades no Brasil, que abordam a gestão de resíduos eletroeletrônicos. Entretanto, Morales (2014) relata que a Universidade Federal do ABC, criou o Projeto de Computadores para Inclusão, neste programa os computadores são recondicionados e peças e partes não aproveitados são encaminhados para instituições cadastradas, que reaproveitam estes materiais.

De fato, um importante projeto de reciclagem de resíduos eletroeletrônicos é o CEDIR da Universidade de São Paulo, daí a importância de se compreender melhor toda a sistemática de gestão de resíduos eletroeletrônicos desta universidade. As universidades em geral são grandes geradoras de REEE, devido à elevada demanda de consumo de equipamentos. Portanto, gerenciar estes REEE é de fato um grande desafio, destacando-se a questão referente ao patrimoniado, armazenamento, uso, manuseio e descarte ambiental sustentável, são somente alguns destes desafios, e muitas universidades estão estabelecendo programas de gerenciamento dos REEE.

Diniz (2016) pesquisou algumas instituições públicas de ensino e pesquisa, que iniciaram o desenvolvimento de projetos pilotos para a logística reversa de uma determinada categoria de REEE, muito presente em sua realidade: os equipamentos eletrônicos de informática. Por meio de uma pesquisa qualitativa descritiva com aplicação da técnica de benchmarking, que consiste em um processo de busca das melhores práticas visando o melhor desempenho, sendo uma ferramenta de gestão de empresas, a autora estudou os procedimentos instituídos nas seguintes Universidades: Universidade Federal de Ouro Preto/MG (UFOP), Universidade Federal de Lavras/MG (UFLA), Universidade Federal de Minas Gerais/MG (UFMG) e 
Universidade de São Paulo (USP) para o desfazimento dos seus resíduos eletrônicos de informática, sugerindo-se também um aprimoramento do processo utilizado pela Universidade Federal de Viçosa-MG (UFV). Além disso, a autora relata que estas universidades apresentam manuais e fluxogramas dos processos de gestão de resíduos eletroeletrônicos, como também disponibilizam em seus sites informações aos interessados de seus programas, além de registros e acompanhamentos por meio de um sistema de controle de patrimônio. Também ela ressalta a existência nestas universidades de comissões especiais designadas para fazer toda a gestão e o gerenciamento dos resíduos eletroeletrônicos.

A gestão de resíduos de equipamentos de informática em universidades públicas se caracteriza por um grande volume de equipamentos obsoletos, que permanecem armazenados por longos períodos e cuja destinação principal ainda é a doação (RIBEIRO, 2017). Panizzon et al. (2017) avaliaram a geração de REEE em uma instituição de ensino superior particular, localizada no estado do Rio Grande do Sul. Estes identificaram 51.066 equipamentos eletroeletrônicos e que o principal REEE gerado pela instituição são equipamentos de informática e telecomunicações $(48,2 \%)$, seguido pelos grandes eletrodomésticos $(14,4 \%)$, instrumentos de monitoramento (13,3\%), ferramentas elétricas e eletrônicas $(10,9 \%)$ e equipamentos de consumo $(9,8 \%)$. A maior parte do $\operatorname{REEE}(29,3 \%)$ da instituição, são gerados no bloco administrativo da universidade, seguido pelas salas de informática (17,3\%). Esses dois setores se caracterizam por utilizarem REEE de rápida obsolescência, diferentemente de outras áreas, como: Ciências Biológicas e Exatas, devido ao uso de equipamentos analíticos com ciclos de vida maior, acabam gerando menos REEE.

Um dos problemas enfrentados pelas instituições públicas de ensino no Brasil é a questão do manuseio e tratamento corretos de resíduos de equipamentos eletroeletrônicos. As instituições não seguem normativas padrões de gestão destes resíduos. Um exemplo dessa situação pode ser encontrado na Universidade Federal de Itajubá (UNIFEI) em Minas Gerais. Devido à falta de tal modelo de gestão, o armazém da universidade encontra-se com capacidade máxima de armazenamento, sendo incapaz de receber novos equipamentos (PAES et al., 2016). Daí a importância de se estabelecer estratégias e protocolos para a gestão correta dos resíduos eletroeletrônicos nas universidades.

Salientou-se que, a PNRS (BRASIL, 2010), é um marco regulatório fundamental para o Brasil, todavia sua aplicabilidade no ponto de vista de ações práticas ainda é muito incipiente, carecendo muito rapidamente evoluir. Os setores produtivos apesar da existência de regulamentações, na prática não são cobrados para estabelecer seus sistemas de logística reversa. O pouco que é executado no país, restringe-se as iniciativas de prefeituras e cooperativas de catadores e ainda outros grupos informais. Em relação aos resíduos eletroeletrônicos este cenário ainda é pior e pouquíssimas empresas desenvolvem sistemas de gestão. $\mathrm{O}$ crescimento na geração destes resíduos no mundo e no Brasil é evidente demandando cada vez, soluções adequadas e sustentáveis para a gestão destes resíduos como um todo (UNU, 2017).

Alguns países, como: China, Índia e África do Sul apresentam produções em grandes escalas e inundam os mercados mundiais com quantidades e variedades de produtos eletroeletrônicos, muitas vezes com obsolescência programada, resultando em grandes volumes de descarte, impactando negativamente o meio ambiente e a saúde pública pela presença de resíduos perigosos e tóxicos (BARROS, 2012; ARAÚJO et 
al., 2012; GUTBERLET, 2015).

Nas universidades em geral, é de fato um grande desafio gerenciar os REEE, pois necessita envolver vários departamentos para se estabelecer um programa de Reúso e reciclagem, entretanto, mesmo com todas as dificuldades muitas universidades estão estabelecendo seus programas de gerenciamento dos REEE (LEITE, 2003; LEITE, 2017; PEREIRA et al., 2011; GERBASE et al., 2012; CARVALHO et al., 2014; CARVALHO, 2015).

Carvalho et al. (2014) destacam que no Brasil, algumas empresas encontraram na reciclagem de aparelhos descartados uma boa oportunidade de mercado, com valor econômico agregado e facilidade de venda. No entanto, é importante frisar que o processo de reciclagem do REEE é diferenciado, exigindo técnicas de separação, trituração e limpeza para prover a reinserção da matéria-prima com qualidade na fabricação de novos produtos, sendo, portanto, imprescindível promover uma destinação adequada dos equipamentos, que estão obsoletos nas residências, empresas, escritórios e Universidades.

Conforme salientam Veit et al. (2014), o processo de reciclagem converge para a prática da logística reversa. Com a logística reversa é necessário analisar toda a cadeia produtiva de um produto, incluindo seu processo de produção e o consumo de insumos, matéria-prima e recursos naturais, logística e distribuição e pós-consumo. Dessa forma, a logística reversa auxilia no retorno de produtos consumidos ou não utilizados, através de canais de distribuição, elaborando o planejamento, e controlando o fluxo inverso do processo produtivo, e introduzindo valor aos produtos gerados, reintegrando-os ao método produtivo e de negócios (PEREIRA et al., 2011).

Conforme salienta Bachi (2013) países do continente Africano e Asiático importam material eletroeletrônico fora de uso, para destinar a campanhas e programas de inclusão digital, já que os valores agregados desses materiais são baixos. Além disso, ocorre a exportação ilegal de resíduos eletroeletrônicos para países da África como Nigéria e Quênia., devido a legislação fraca, permitindo a entrada desses materiais nos países, revelando um grave problema socioambiental, já que as contaminações ambientais diretamente devidas ao descarte dos resíduos eletroeletrônicos ocorrem nesses locais, com manuseio incorreto dessas sobras no ambiente.

De acordo com Leite (2017), os primeiros estudos sobre logística reversa datam desde a década de 70 , em que se priorizava o retorno dos bens direcionados para o processo de reciclagem dos materiais. No entanto, o aumento da velocidade de descarte dos produtos consumidos, e a escassez de canais de distribuição reversos ou coletores de pós-consumo bem estruturados e organizados, provocam desequilíbrio entre as quantidades descartadas e as reaproveitadas, aumentando a geração de resíduos descartados e, portanto, a necessidade de se estabelecer canais de logística reversa e ciclos mais sustentáveis (CARVALHO, 2015).

O CEDIR consegue realizar práticas sustentáveis, reaproveitando os REEE, promovendo a destinação adequada dos materiais, aumentando sua vida útil, evitando-se seu descarte prematuro. Para estabelecer um processo de reciclagem, é necessário organizar o sistema de coleta diferenciada, que é uma tarefa difícil, principalmente, em se tratando do Brasil, pois ainda não se tem a cultura da reciclagem, falta educação, 
participação e cooperação, o governo não cobra efetivamente, a sociedade não exige e as empresas estão tranquilas e acomodadas com o cenário atual (MORALES, 2014). Existem muitos desafios relacionados ao planejamento, políticas públicas e implementações da reciclagem em geral (DEMAJOROVIC et al., 2016).

Araújo et al. (2012) relataram que para implantação de sistemas de reciclagem e gestão adequada de resíduos eletroeletrônicos, são necessárias as seguintes ações: estabelecimento de legislação específica sobre REEE, com regulamentações adequadas para as diferentes condições do mercado regional, estabelecimento de controles efetivos e seguros, estruturação de um fluxo logístico reverso, com logística reversa e canais adequados para cada tipo de produto, que devem ser competitivos e ambientalmente corretos e tecnologicamente bem estruturado e incentivos para a criação de associações de catadores e reciclagem, por meio de incentivos fiscais, econômicos e financeiros.

\section{METODOLOGIA}

Este trabalho se trata de um estudo de caso, no qual foi investigado o Centro de Descarte e Reúso de Resíduos de Informação, o CEDIR, na Universidade de São Paulo (USP). Na primeira parte do trabalho realizou-se a revisão da literatura sobre resíduos de equipamentos eletroeletrônicos e, especificamente a gestão destes resíduos. A revisão foi realizada em publicações científicas, pesquisando-se: livros, trabalhos de conclusão de curso, dissertações e teses e em bases indexadas digitais: 'periódicos Capes', 'teses e dissertações USP' e 'Scielo'. A busca foi feita pelo título (palavras-chave) com: 'resíduos eletroeletrônicos', 'resíduos eletrônicos', 'REEE' e 'E-Waste'. Também foram realizadas buscas na internet, através ferramenta Google, utilizando a seguinte expressão: 'Resíduos Eletroeletrônicos em Universidade'. Também se realizou pesquisas documentais, incluindo normas, regulamentações, leis etc..

A segunda etapa do trabalho, foi realizada no CEDIR-USP, por meio de uma visita técnica acompanhada pelo coordenador responsável deste centro, para levantamento e compreensão da gestão dos resíduos eletroeletrônicos, enfatizando-se alguns aspectos principais, como: recepção dos resíduos pelo centro, controle dos resíduos, processamento dos sistemas de reciclagem, reúso e reaproveitamento e descarte/destino destes resíduos.

Também foram obtidos e avaliados materiais de comunicação e divulgação do CEDIR disponíveis em seu site e ainda um conjunto de dados e informações disponibilizados pelo centro durante o trabalho de campo, constituindo-se em planilhas eletrônicas de controle da gestão do centro como um todo. A pesquisa enfatizou o estudo de caso único, representando uma visão geral do projeto CEDIR, atendimento a algumas diretrizes e perguntas mencionadas no item segunda etapa do trabalho e procedimentos contemplando a visita de campo e análise em geral.

E a terceira etapa, foi a definição de diretrizes e estratégias, visando uma potencial futura implementação de um centro de reúso e reciclagem de REEE na UNIFESP, Campus Diadema, sendo utilizado para esta análise a aplicação da metodologia SWOT (DAMIAN, 2015), identificando os fatores internos e externos quanto as forças, oportunidades, fraquezas e ameaças, quanto ao estabelecimento de um plano de gerenciamento de REEE. 


\section{RESULTADOS E DISCUSSÃO}

Os resultados obtidos da pesquisa e a discussão estão organizados da seguinte maneira: apresentação do Centro de Descarte e Reúso de Resíduos de Informática (CEDIR-USP) e análise das potencialidades e desafios da gestão de resíduos de equipamentos eletroeletrônicos na UNIFESP - Campus Diadema.

\section{Centro de Descarte e Reúso de Resíduos de Informática (CEDIR-USP)}

A Universidade de São Paulo (USP) é uma universidade pública, mantida pelo estado de São Paulo e criada em 1934. Em 2012, foi criada no campus da USP, a Superintendência de Gestão Ambiental para promover ações de sustentabilidade em geral e, a partir disso foi estabelecido um Grupo de Trabalho de Gerenciamento de Resíduos, tendo como objetivo gerenciar os diferentes resíduos da Universidade. Um projeto importante na universidade é o 'USP Recicla', que busca ações de valorização de resíduos como um todo. O crescente aumento de resíduos eletroeletrônicos na universidade e a inexistência de políticas internas de gestão destes resíduos, motivou o desenvolvimento do CEDIR, o Centro de Descarte e Reúso de Resíduos de Informática. Inaugurado no ano de 2009, o CEDIR implementou práticas de reúso e descarte sustentável de resíduos eletroeletrônicos no Centro de Computação Eletrônica da USP e demais unidades dos diversos campus da universidade. O CEDIR faz parte da Superintendência de Tecnologia da Informação na USP.

O CEDIR foi idealizado pela professora Dra. Tereza Cristina de Brito Carvalho (CARVALHO, 2015) em parceria com o Instituto de Massachusetts (MIT) nos Estados Unidos, criou-se um 'selo verde', com objetivo de se adquirir equipamentos de informática e telecomunicações verdes, objetivando-se diminuir a quantidade de resíduos eletroeletrônicos. O CEDIR é responsável pela triagem, classificação, segregação, reúso e encaminhamento dos resíduos eletroeletrônicos para empresas parceiras de reciclagem. O centro está instalado em um galpão na USP de $200 \mathrm{~m}^{2}$ local em que as atividades operacionais são desenvolvidas.

Morales (2014) apontou alguns desafios quanto a gestão do CEDIR, citando os seguintes: dificuldade na participação de colaboradores, que nem sempre estavam prontamente disponíveis, custos de processamento de reciclagem são altos, daí muitas empresas se especializaram em reciclar somente alguns materiais. Portanto, outros materiais acabam não sendo reciclados, o material bem segregado, ou seja, sem muita mistura apresenta melhor valor comercial, é necessário educação quanto ao descarte correto pela comunidade universitária como um todo, permitindo se estabelecer um fluxo frequente de materiais ao centro, é necessário estabelecer parcerias com empresas de reciclagem, garantindo o destino adequado e sustentável dos materiais como um todo, além da definição de procedimentos de coleta e encaminhamento dos resíduos eletroeletrônicos ao centro e a identificação de entidades assistenciais aptas a participação do programa.

As dificuldades encontradas pelas universidades na gestão dos bens de informática e seus resíduos são muitas: não há procedimentos e normatização definidos, a classificação e especificação dos bens de 
informática em planilha é um processo muito detalhado e burocrático, a legislação não favorece a destinação ambientalmente adequada, existe burocracia no processo de desfazimento, falta de espaço para armazenar os bens enquanto não há o desfazimento, preço da sucata muito desvalorizado, falta de envolvimento/comprometimento dos gestores competentes e não há políticas ambientais institucionais para gestão dos REEE (MORALES, 2014).

O CEDIR funciona a partir das seguintes ações fundamentais: coleta de equipamentos eletroeletrônicos, identificação e encaminhamento de equipamentos considerados ainda operacionais para projetos sociais, desmontagem de equipamentos e classificação de seus componentes para encaminhamento as empresas parceiras de reciclagem (Figura 1).

Segundo Morales (2014), o investimento inicial no CEDIR foi de R\$ 230.602,00 (incluindo infraestrutura, ferramentas, equipamentos e reforma do espaço/galpão), as despesas fixas mensais foram de $R \$ 17.200,00$, considerando-se contas de energia, água e telefone, salários (1 técnico e 2 auxiliares) e materiais de consumo, resultando em um valor anual de cerca de $\mathrm{R} \$ 206.400,00$. Referente ao ano de 2012, constava uma receita anual de $\mathrm{R} \$ 288.000,00$, considerando um fluxo de 600 computadores por mês ao preço de $\mathrm{R} \$ 40,00$ por micro. Estimava-se que em 3 anos, o investimento inicial seria amortizado. Na visita não foi possível checar o cenário atual destas informações, pois no momento o CEDIR passa por um período de reestruturação e muitas informações e dados não estão disponíveis no momento. A Figura 1 mostra as etapas do manejo dos resíduos eletroeletrônicos no CEDIR, destacam-se os seguintes processos: (i) primeira etapa: coleta e triagem: o equipamento é recepcionado, ocorre a primeira análise e é checado a viabilidade de aproveitamento do equipamento. Em caso positivo, ele é encaminhado a um dos parceiros sociais na forma de empréstimo (isto, para garantir a devolução dele), garantindo sempre um destino correto e sustentável ao equipamento. $O$ equipamento não aproveitado é encaminhado para a etapa de categorização; (ii) segunda etapa: categorização: o equipamento é pesado, desmontado e separado por tipo de material (plástico, metal, placas eletrônicas, cabos etc.). Os materiais do mesmo tipo são descaracterizados e compactados para reduzir seu volume e facilitar seu armazenamento e (iii) terceira etapa: reciclagem: os materiais categorizados são armazenados até o seu recolhimento pelas empresas parceiras de reciclagem do programa.

No CEDIR foi possível identificar a presença de uma grande variedade de resíduos eletroeletrônicos, destacando-se: CPUs, impressoras, monitores, nobreaks, notebooks, scanners, telefones (portáteis e fixos) e outros tipos de equipamentos, como roteadores, rádios, DVDs, teclados, caixas de som etc. A Tabela 1 mostra alguns números em relação ao recebimento de REE pelo CEDIR, destacando-se a presença de monitores e CPUs (processadores). Estes equipamentos são oriundos da própria universidade, de pessoas físicas, alunos da USP, outras instituições de ensino (público e privado) e organizações não-governamentais (ONGs). Os dados referentes aos anos de 2013 e 2014 infelizmente não estavam disponíveis, dificuldades na gestão do CEDIR impossibilitaram o registro das informações. No ano de 2015, o CEDIR recebeu 8.842 equipamentos eletroeletrônicos, correspondendo a aproximadamente 80 toneladas de REEE, mantendo-se em maior quantidade a presença de processadores e monitores. Foram doados pelo CEDIR as associações sociais 
parceiras do programa, 517 equipamentos eletroeletrônicos, destaque para a doação de 250 processadores e 230 monitores. Foi possível notar a existência de muita variação nos registros de dados no CEDIR, aspecto que dificultou muito a execução de maiores análises com os poucos dados disponíveis. Alguns anos existia somente dados de totais de recebimento, em outros anos não foi possível obter nenhuma informação.

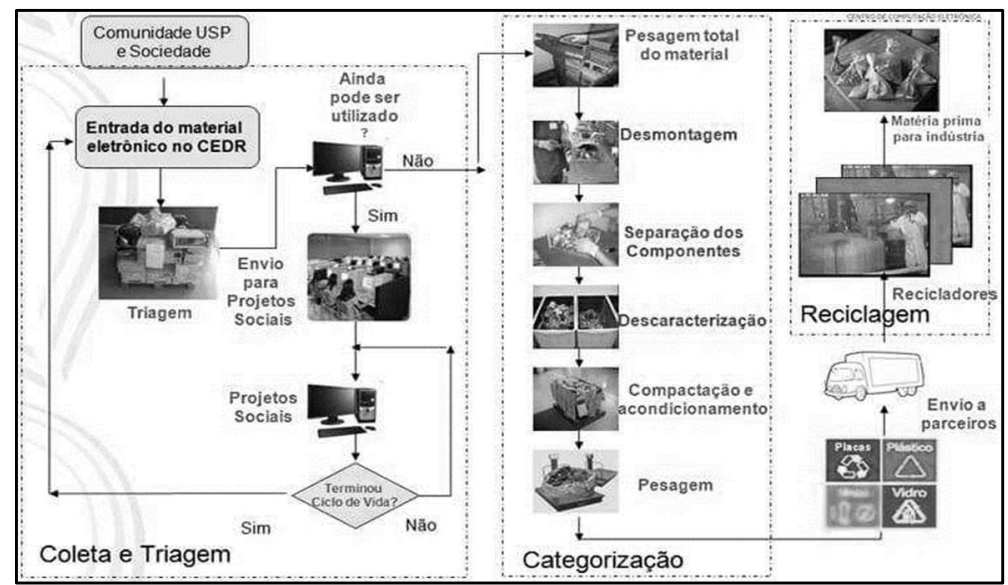

Figura 1: Fluxograma das Etapas de Gestão dos Resíduos Eletroeletrônicos no CEDIR-USP. Fonte: Morales (2014).

Foi possível analisar o fluxo mensal de REEE e, a partir de 2016 não foi possível obter mais nenhuma informação. O CEDIR vem sofrendo vários problemas relacionados a demissões, greves e mudanças internas e estruturais da própria universidade (USP), aspectos que dificultam e prejudicam a gestão do centro. Atualmente, o CEDIR foi bastante afetado pelo processo de demissões voluntárias da USP, resultando na redução drástica de funcionários do centro, como também mudanças constantes de localização, com reduções no espaço físico, que influenciaram muito no recebimento de equipamentos eletroeletrônicos e, principalmente, gestão do centro como um todo. O que dá, de fato para dizer é que o conjunto processadormonitor é o resíduo eletroeletrônico mais representativo do centro, demandando maior gestão e processamento.

Tabela 1: Quantidade de REEE recebido pelo CEDIR-USP.

\begin{tabular}{|c|c|c|c|c|c|}
\hline REEE & Ano & & & & Total \\
\hline & 2010 & 2011 & 2012 & 2015 & \\
\hline CPUS & 2.546 & 2.679 & 2.033 & 3.124 & 10.382 \\
\hline Impressoras & 1.162 & 1.183 & 993 & 1.144 & 4.482 \\
\hline Monitores & 3.078 & 3.295 & 2.120 & 1.685 & 10.178 \\
\hline Nobreaks & 188 & 266 & 325 & 493 & 1.272 \\
\hline Notebooks & 103 & 133 & 160 & 762 & 1.158 \\
\hline Outros (roteadores, rádios, televisores, DVD's, teclados, mouses, caixas de som etc.) & 2.402 & 1.002 & 535 & 1.374 & 5.313 \\
\hline \multicolumn{6}{|l|}{ Scanners } \\
\hline \multicolumn{6}{|l|}{ Telefones (celulares e fixos) } \\
\hline Total & & & & & \\
\hline
\end{tabular}

O CEDIR cumpre um papel socioambiental importantíssimo na universidade, pois promove práticas sustentáveis de gestão dos resíduos eletroeletrônicos, gerando benefícios ambientais, sociais e econômicos. Estabelece manejo adequado aos equipamentos eletroeletrônicos, evita o descarte inadequado destes resíduos, cria canais de logística reversa, com o reúso, reaproveitamento e encaminhamento para sistemas de reciclagem, possibilitando a recuperação de materiais em geral e até metais preciosos. Entretanto, manter em funcionamento este centro, não é nada fácil, mesmo considerando a USP, que é uma instituição já 
consolidada e uma das maiores e melhores universidades do mundo.

\section{Análise das Potencialidades e Desafios da Gestão de Resíduos de Equipamentos Eletroeletrônicos na UNIFESP - Campus Diadema}

Com base na experiência do CEDIR, é possível refletir um pouco sobre uma futura implantação de um centro de reúso e descarte de resíduos eletroeletrônicos na UNIFESP, Campus Diadema. Contatando os setores internos de gestão do Campus Diadema, incluindo a Tecnologia da Informação (TI) e o Patrimônio, não foi observado nenhuma prática de gestão dos resíduos eletroeletrônicos. Na própria constituição da TI, constituída pela Portaria no 523 de 14 de março de 2012 em seu Art. 2o - A Divisão de Tecnologia da Informação tem por missão as atividades relacionadas com a aplicação e desenvolvimento de ações em Tecnologia da Informação, incluindo infraestrutura e rede, softwares, administração dos laboratórios de informática, assistência e suporte, desenvolvimento e apoio lógico, com elevados padrões de qualidade e excelência. Não apresenta como atividade a gestão dos resíduos de equipamentos eletroeletrônicos. Portanto, não existem pelo menos formalmente dados sobre os resíduos eletroeletrônicos no Campus.

Em relação ao setor de Patrimônio, também não se encontrou nenhuma prática de gestão dos resíduos eletroeletrônicos. Mas, foi encontrado no conjunto de suas atribuições, a denominação normativa de processar o desfazimento por uso, manutenção ou recuperação antieconômica, obsolescência, ou por ser irrecuperável o bem, que inclui os equipamentos eletroeletrônicos. Isto é importante, pois efetivamente para o manuseio de qualquer bem institucional, caberá a este setor, inicialmente, realizar o desfazimento patrimonial dele, permitindo posteriormente o manejo deste bem qualquer.

Encontrou-se na UNIFESP, o Plano de Gestão de Logística Sustentável - 2019 (SÃO PAULO, 2012) tendo como base o disposto no Decreto no 7.746/2012 e seguindo a Instrução Normativa SLTI/MP no 10/2012 elaborado pelo Departamento de Gestão e Segurança Ambiental da UNIFESP (DGA-UNIFESP), integrante da Reitoria da UNIFESP. O presente documento trata-se de um instrumento de planejamento, que visa instituir práticas de sustentabilidade, otimização de gastos, melhoria nos serviços e orientações para as contratações e compras realizadas. Mas, este documento não faz menção a gestão de resíduos eletroeletrônicos, no entanto, considera outras ações no setor ambiental, no Campus da UNIFESP da Baixada Santista, o documento considera a meta de aumentar aproximadamente $10 \%$ a destinação adequada dos resíduos, e no Campus Diadema, faz menção ao fortalecimento do programa de coleta seletiva da unidade, por meio da promoção de campanhas de educação ambiental sobre a separação adequada dos resíduos (SÃO PAULO, 2012). O Plano de Gestão de Logística Sustentável - 2019, da UNIFESP aplica a gestão e destinação adequada dos Resíduos Eletroeletrônicos no Campus Osasco, coordenada pelo departamento de Gestão Ambiental, da Diretoria Administrativa, do setor de Patrimônio e de Tecnologia de Informação (SÃO PAULO, 2012).

Outro documento encontrado foi a Resolução no 118, de 2015, que institui a Política de Resíduos Sólidos da Universidade Federal de São Paulo (PRS-UNIFESP) e dá outras providências (SÃO PAULO, 2012). Destaca-se também, que neste documento é mencionado a possibilidade de realizar capacitações temáticas no âmbito da sustentabilidade no Campus Diadema, com a gestão e disposição de novos tipos de resíduos 
eletroeletrônicos, cápsulas de café, bitucas de cigarro, isopor, madeira, baterias de carro e celular e lâmpadas fluorescentes (SÃO PAULO, 2012). No Art. 26 desta resolução, determina-se que todos os Campi da UNIFESP, Hospital Universitário, Reitoria, órgãos de Integração, Órgãos Complementares e os prestadores de serviços deverão cumprir os preceitos normativos da legislação vigente relativa à estruturação e implementação de sistemas de logística reversa para os seguintes tipos de resíduos: pilhas e baterias, pneus, óleos lubrificantes, seus resíduos e embalagens, lâmpadas fluorescentes, de vapor de sódio e mercúrio e de luz mista e resíduos eletroeletrônicos/tecnológicos e seus componentes.

Percebe-se que na prática, efetivamente não se realiza nada no sentido de atendimento desta resolução no Campus Diadema em relação a gestão dos resíduos eletroeletrônicos. Nesse sentido, elaborouse alguns questionamentos inseridos no formato de desafios e algumas sugestões para uma futura implantação do centro de gestão (reúso e descarte) de resíduos eletroeletrônicos na UNIFESP, Campus Diadema.

Como possíveis desafios, destacam-se os seguintes: realização de um levantamento qualiquantitativo dos resíduos de equipamentos eletroeletrônicos, caracterização do cenário atual relacionado aos locais e condições em termos de infraestrutura do armazenamento destes resíduos, disponibilidade financeira e capital humano para implementação de um centro de Reúso e reciclagem, desenvolvimento de um programa de comunicação e educação ambiental para toda a comunidade acadêmica, desenvolvimento de parcerias com o município, instituições não governamentais, cooperativas de catadores e reciclagem e necessidade de integração entre os departamentos do Campus, incluindo a Tecnologia de Informação, Gestão Ambiental e Patrimônio.

Como potenciais práticas, destacam-se as seguintes: criação de uma base de dados no formato de uma plataforma digital para a comunidade acadêmica, registrar a ocorrência de resíduos eletroeletrônicos obsoletos e/ou mau funcionamento, realização por parte da Tecnologia da Informação de um inventário da condição técnica de equipamentos eletroeletrônicos, classificando-os como: recuperável ou irrecuperável. O recuperável demandaria formatação, atualização e aperfeiçoamento, podendo ficar apto ao reúso interno (Campus) ou externo (doação) as instituições sociais locais. Já o irrecuperável, devido a obsolescência tecnológica ou condição antieconômica, seria disponibilizado (descarte) as instituições de reciclagem.

Essas caracterizações iniciais demonstram, de um modo geral, diversos desafios e potencialidades, incluindo diversos processos internos e externos e condições que permitem ou dificultam a implementação e funcionamento de um centro de reúso e reciclagem de resíduos de equipamentos eletroeletrônicos. Nesse sentido, a análise SWOT é um método de planejamento estratégico, que permite escolher determinados rumos e direções, identificando as forças, fraquezas, ameaças e oportunidades, facilitando a tomada de decisões. O Quadro 1 apresenta a matriz das principais forças, fraquezas, oportunidades e ameaças da implementação futura de um centro de reúso e reciclagem de resíduos de equipamentos eletroeletrônicos no Campus Diadema. No Campus Diadema destaca-se como forças, a existência de programas de coleta seletiva e valorização de resíduos, parcerias com a prefeitura de Diadema e organizações e instituições sociais locais. No entanto, as maiores fraquezas ocorrem no âmbito interno, pois o Campus encontra-se em obras 
de implantação e seu funcionamento ocorre em unidades universitárias distribuídas pelo município de Diadema, quase nem sempre em condições adequadas em termos de infraestrutura geral. Uma das carências significativa é a falta de espaços adequados para armazenamento de resíduos de equipamentos eletroeletrônicos. Também as interações departamentais não são tão simples, pois estas também se encontram alocadas em diferentes espaços físicos dentro das unidades universitárias, aspecto que dificulta a total comunicação e interações entre os departamentos. Caracterizamos as dificuldades em relação ao armazenamento correto dos REEE, o sistema de controle e, principalmente fluxo de despatrimoniamento dos equipamentos eletroeletrônicos e inexistência de registros quali-quantitativos do volume de REEE.

Quadro 1: SWOT de um potencial centro de reúso e reciclagem de REEE no Campus Diadema.

\begin{tabular}{|c|c|c|}
\hline & Fatores positivos & Fatores negativos \\
\hline $\begin{array}{l}\text { Fatores } \\
\text { internos }\end{array}$ & $\begin{array}{l}\text { Forças } \\
\text { Existência de programas de segregação de resíduos } \\
\text { no Campus; } \\
\text { Existência de normativas para segregação e coleta } \\
\text { seletiva de resíduos no Campus; } \\
\text { Parcerias institucionais com a prefeitura municipal } \\
\text { de Diadema; } \\
\text { Presença de projetos extensionistas e cursinhos } \\
\text { populares no Campus e em Diadema; } \\
\text { Parcerias institucionais com instituições sociais. }\end{array}$ & $\begin{array}{l}\text { Fraquezas } \\
\text { Ausência de um programa específico para gestão de REEE no Campus; } \\
\text { Ausência de um plano de educação ambiental institucional no Campus, } \\
\text { referente a gestão de REEE; } \\
\text { Inexistência de espaços físicos adequados para a instalação de galpões de } \\
\text { manuseio e armazenado correto de REEE no Campus; } \\
\text { Inexistência de um processo sistêmico e rápido de despatrimoniamento de } \\
\text { REEE; } \\
\text { Inexistência de um sistema de monitoramento de REEE; } \\
\text { Inexistência de dados de geração de REEE no Campus; } \\
\text { Inexistência de um sistema de interação de informações em REEE, incluindo } \\
\text { os atores: Departamento de Tecnologia da Informação, Gestão Ambiental e } \\
\text { Patrimônio; } \\
\text { Inexistência de recursos financeiros e capital humano para implementação } \\
\text { de ações de gestão de REEE. }\end{array}$ \\
\hline $\begin{array}{l}\text { Fatores } \\
\text { externos }\end{array}$ & $\begin{array}{l}\text { Oportunidades } \\
\text { Incentivos da Política Nacional de Resíduos Sólidos } \\
\text { para reúso e reciclagem de REEE; } \\
\text { Existência de cooperativas de catadores no } \\
\text { município de Diadema; } \\
\text { Existência de parcerias em projetos institucionais } \\
\text { Universidade, Campus Diadema - Prefeitura de } \\
\text { Diadema; } \\
\text { Existência de cooperativa de reciclagem de REE no } \\
\text { município de Diadema; } \\
\text { Potencialidades quanto ao pagamento de créditos } \\
\text { de logística reversa. }\end{array}$ & $\begin{array}{l}\text { Ameaças } \\
\text { As cooperativas de catadores e reciclagem não dispõem de infraestrutura e } \\
\text { procedimentos adequados para a gestão correta de REEE; } \\
\text { A prefeitura de Diadema não incentiva e nem desenvolve ações de gestão } \\
\text { adequada de REEE; } \\
\text { Crise econômica e o mercado de reciclagem valoriza muito pouco os REEE; } \\
\text { As indústrias fabricantes não fazem investimentos na gestão de REEE; } \\
\text { Os comércios atacadista e varejista não desenvolvem iniciativas de gestão } \\
\text { de REEE; } \\
\text { Penalidades normativas em relação ao descumprimento da Política Nacional } \\
\text { de Resíduos Sólidos. }\end{array}$ \\
\hline
\end{tabular}

A criação de um centro de reúso e reciclagem de REEE no Campus Diadema, nos moldes do CEDIRUSP, demandaria espaço físico, infraestrutura (galpão, ferramentas etc.) e mão-de-obra, demandas que no momento inviabilizaria totalmente sua implementação. Entretanto, um centro menos complexo e, principalmente com estrutura apoiada nas parcerias já consolidadas, incluindo a Prefeitura de Diadema e a cooperativa de catadores (Cooperlimpa) e uma potencial parceria com a instituição (Casa do Metal) recicladora de REEE presente no município de Diadema, possibilitaria o desenvolvimento de um programa de gestão de REEE na UNIFESP, Campus Diadema. O Campus Diadema também já mantém programas extensionistas no município de Diadema, como o Programa Articul@ções, que cuida de cursinhos e, poderia ser uma instituição para recepção de computadores recuperados.

\section{CONCLUSÕES}

O CEDIR-USP implementa práticas de reúso e reciclagem de REEE, atendendo as demandas da universidade, porém é uma atividade que também se estende a comunidade em geral. É uma iniciativa 
importante, pois ainda não são muitas instituições de ensino superior que realizam tais práticas. Os benefícios são inúmeros: redução de resíduos de equipamentos eletroeletrônicos descartados de maneira inadequada, reciclagem de materiais, educação ambiental, apoio a entidades sociais e instituições recicladoras, parceiras com cooperativas de catadores e aplicação da PNRS.

Foi possível verificar a existência de várias parcerias do CEDIR-USP com outras instituições da própria USP e externas, como: Laboratório de Sustentabilidade em Tecnologia de Informação e Comunicação (LASSU) da Escola Politécnica da USP e o Instituto GEA-Ética e Meio Ambiente, organização não-governamental que trabalha com coleta seletiva, reciclagem e formação de cooperativas de catadores e reciclagem. Destaca-se também o caráter educacional do programa CEDIR-USP, fomentando práticas, capacitações e divulgação de informações, a outras iniciativas e parceiras com cooperativas de reciclagem.

Atualmente, o CEDIR-USP passa por um momento de transição, com muitas incertezas quanto ao seu espaço físico dentro da USP e, principalmente funcionários. As instituições de ensino superior, produzem muitos REEE, principalmente, processadores e monitores, daí a importância de se adotar práticas sustentáveis de gerenciamento destes resíduos como um todo. Na UNIFESP, Campus Diadema ainda não existem práticas de gestão de REEE, sendo possível verificar a ocorrência de algumas regulamentações normativas a este assunto.

A análise SWOT apontou a existência de várias fraquezas e ameaças, entretanto, também direcionou forças e, principalmente excelentes oportunidades para a implementação de um centro de reúso e de reciclagem de REEE. Dificuldades relacionadas a infraestrutura, despatrimoniamento de equipamentos eletroeletrônicos e interações departamentais, são algumas barreiras importantes, mas, por outro lado, oportunidades mencionadas, como: existência de programas internos de separação de resíduos, parcerias com o município de Diadema, convênios com cooperativas de catadores e reciclagem, podem facilitar a implementação de um centro no Campus Diadema.

Como recomendação para trabalhos futuros, sugere-se a realização de um estudo para caracterização quali-quantitativa de REEE na UNIFESP, Campus Diadema, apoiando uma melhor definição e planejamento de um plano de gerenciamento de REEE. Finalmente, o presente trabalho aponta algumas estratégias adequadas possíveis, para o desenvolvimento de práticas corretas a gestão de REEE, incluindo ações de reúso e reciclagem.

\section{REFERÊNCIAS}

ABDI. Agência Brasileira de Desenvolvimento Industrial. Logística Reversa de Equipamentos Eletroeletrônicos Análise de Viabilidade Técnica e Econômica. São Paulo: ABDI, 2013.

ARAÚJO, M. G.; MAGRINI, A.; MAHLER, C. F.; BILITEWSKI, B.. A model for estimation of potential generation of waste Electrical and electronic equipment in Brazil. Waste Management, v.32, p.335-342, 2012.

BACHI, M. H.. Resíduos Eletrônicos: A relação dos resíduos eletroeletrônicos com a legislação do Brasil. Revista Brasileira de Gestão Ambiental, v.7, n.1, p.1-5, 2013.
BALDÉ, C. P.; FORTI, V.; GRAY, V.; KUEHR, R.; STEGMANN, P. The Global E-waste Monitor 2017: Quantities, Flows and Resources. Bonn: ISWA, 2017.

BARROS, R. T. V.. Elementos de Gestão de Resíduos Sólidos. Belo Horizonte: Tessitura, 2012.

BRASIL. Lei Federal n.12.305. Política Nacional de Resíduos Sólidos. Brasília: DOU, 2010.

BVRIO. Instituto BVRio. Créditos de Logística Reversa: Uma Inovação Socioambiental para Gestão de Resíduos Sólidos 
Urbanos: Estudo de caso da Bolsa de Valores Ambientais BVRio no Brasil. Rio de Janeiro: BVRIO, 2019.

CARVALHO, J. E.. A importância da consensualidade na implementação da Logística Reversa. Dissertação

(Mestrado) - Universidade de São Paulo, São Paulo, 2015.

CARVALHO, T. C. M. B.; XAVIER, L. H.. Gestão de Resíduos Eletroeletrônicos: Uma abordagem prática para a sustentabilidade. Rio de Janeiro: Elsevier, 2014.

CAYUMIL, R.; KHANNA, R.; RAJARAO, R.; MUKHERJEE, P. S.; SAHAJWALLA, V.. Concentration of precious metals during their recovery from electronic waste. Waste Management, v.57, p.121-130, 2016.

DAMIAN, T.. Gestão de Empresa: Tópicos Especiais em Gestão Empresarial. Jundiaí: Paco, 2015.

DEMAJOROVIC, J.; AUGUSTO, E. E. F.; SOUZA, M. T. S.. Reverse logistics of e-waste in developing countries: challenges and prospects for the Brazilian model. Ambiente \& Sociedade, v.19, n.2, p.117-136, 2016.

DINIZ, N. R. F.. Gestão ambiental em instituições públicas de ensino superior: processos de destinação de resíduos eletrônicos de informação. Dissertação (Metrado) Universidade Federal de Viçosa, Florestal, 2016.

FRANCO, R. G.; LANGE, L. C.. Estimativa do fluxo dos resíduos de equipamentos elétricos e eletrônicos no município de Belo Horizonte, Minas Gerais, Brasil. Engenharia Sanitária Ambiental, v.16, n.1, p.73-82, 2011.

GERBASE, A. E.; OLIVEIRA, C. R.. Reciclagem do lixo de informática: uma oportunidade para a química. Química Nova, v.35, n.7, p.1486-1492, 2012.

GUTBERLET, J.. Cooperative urban mining in Brazil: Collective practices in selective household waste collection and recycling. Waste Management, v.45, p.22-31, 2015.

LEITE, P. R.. Logística Reversa: Meio ambiente e Competitividade. São Paulo: Prentice Hall, 2003.

LEITE, P. R.. Logística Reversa: Sustentabilidade e Competitividade. São Paulo: Saraiva, 2017.

MORALES, L. L.. Gestão do Resíduo Eletrônico em
Universidade: Estudo de Caso no Centro de Descarte e Reúso de Resíduos de Informática (CEDIR) USP. Tese (Doutorado) - Universidade de São Paulo, São Paulo, 2014.

OLIVEIRA, C. R.; BERNARDES, A. M.; GERBASE, A. E. Collection and recycling of electronic scrap: $A$ worldwide overview and comparison with the Brazilian situation. Waste Management, v.32, p.1592-1610, 2012.

PAES, C. E.; BERNARDO, M.; LIMA, R. S.; LEAL, F.. Management of Waste Electrical and Electronic Equipment in Brazilian Public Education Institutions: Implementation Through Action Research on a University Campus. Syst Pract Action Res., Springer, v.30, n.4, p.377-393, 2016

PANIZZON, T.; REICHERT, G. A.; SCHNEIDER, V. E.. Avaliação da geração de resíduos de equipamentos eletroeletrônicos (REEEs) em uma universidade particular. Engenharia Sanitária Ambiental, v.22, n.4, p.625-635, 2017.

PEREIRA, A. L.; BOECHAT, C. B.; TADEU, H. F. B.; SILVA, J. T. M.; CAMPOS, P. M. S.. Logística reversa e sustentabilidade. São Paulo: Cengage Learning, 2011.

RIBEIRO, E. L.. Resíduos Eletroeletrônicos no Governo Federal: normas e procedimentos para descarte de materiais de informática: o caso do Centro Federal de Educação Tecnológica do Rio de Janeiro (CEFET/RJ). Dissertação (Mestrado) - Universidade Federal Fluminense, Rio de Janeiro, 2017.

RODRIGUES, A. C.; GUNTHER, W. M. R.; BOSCOV, M. E. G.. Estimativa da geração de resíduos de equipamentos elétricos e eletrônicos de origem domiciliar: proposição de método e aplicação ao município de São Paulo. São Paulo, Brasil. Engenharia Sanitária Ambiental, v.20, n.3, p.437-447, 2015.

SÃO PAULO. Decreto n.7.746. Plano de Gestão de Logística Sustentável. Alterado pelo Decreto n.9.178, de 23 de outubro de 2017. São Paulo: DOE, 2012.

SMA. Secretaria de Meio Ambiente. Cadernos de Educação Ambiental: Resíduos Sólidos. São Paulo: SMA, 2010.

VEIT, H. M.; JUCHNESKI, N. C. F.; SCHERER, J.. Use of gravity separation in metals concentration from printed circuit board scraps. Rem: Revista Escola de Minas, v.67, n.1, p.7379, 2014.

A CBPC - Companhia Brasileira de Produção Científica (CNPJ: 11.221.422/0001-03) detém os direitos materiais desta publicação. Os direitos referem-se à publicação do trabalho em qualquer parte do mundo, incluindo os direitos às renovações, expansões e disseminações da contribuição, bem como outros direitos subsidiários. Todos os trabalhos publicados eletronicamente poderão posteriormente ser publicados em coletâneas impressas sob coordenação da Sustenere Publishing, da Companhia Brasileira de Produção Científica e seus parceiros autorizados. Os (as) autores (as) preservam os direitos autorais, mas não têm permissão para a publicação da contribuição em outro meio, impresso ou digital, em português ou em tradução. 